\title{
A ESTREITA RELAÇÃO ENTRE A CORTE INTERNACIONAL DE JUSTIÇA E O CONSELHO DE SEGURANÇA DAS NAÇÕES UNIDAS
}

\section{THE CLOSE RELATIONSHIP BETWEEN THE INTERNATIONAL COURT OF JUSTICE AND THE UNITED NATIONS SECURITY COUNCIL}

\author{
Fernanda Menezes dos Santos* \\ Luiza Santos Cury Soares** \\ Matheus Felipe Moreira Zanetti***
}

\begin{abstract}
RESUMO
A Corte Internacional de Justiça (CIJ) é o principal órgão jurisdicional da Organização das Nações Unidas, ao passo que o Conselho de Segurança (CSNU) é o órgão permanente da organização, com a função de manutenção da paz e da segurança internacional. Ambos representam os órgãos mais importantes e prestigiados da instituição, de modo que sua relação e comunicação é extremamente relevante e definida pela própria Carta das Nações Unidas e pelo Estatuto da Corte Internacional de Justiça. Nesse sentido, faz-se necessário compreender como essa relação se dá, de maneira que o objetivo do presente artigo é analisar a estreita relação entre a CIJ e o CSNU, o que se faz a partir das regras definidas pelas citadas normas internacionais, além de casos concretos que envolvam tais órgãos. Como referencial teórico, utiliza-se a doutrina dos mais renomados juristas e estudiosos das Relações Internacionais, os quais trabalham com os conceitos necessários para se compreender o papel prestado por tais órgãos e suas principais regras procedimentais e de funcionamento. Ressalta-se, como exemplo, a utilização da doutrina de Augusto Cançado Trindade e Malcolm Shaw. A metodologia utilizada parte do modelo jurídico-compreensivo, com análise de dados primários, como normas internacionais, e dados secundários, como a doutrina. Tem-se, com isso, que o presente artigo demonstra-se como demasiado pertinente para o campo do Direito Internacional, uma vez que diz respeito à comunicação e relação entre os dois principais órgãos do sistema internacional, a partir das quais é possível verificar a evolução do Direito Internacional e os mecanismos dispostos pelas Nações Unidas para a manutenção da paz e da segurança internacional.
\end{abstract}

Palavras-chave: Corte Internacional de Justiça. Conselho de Segurança. Organização das Nações Unidas. Caso Estreito de Corfu.

\footnotetext{
Artigo submetido em 14 de junho de 2021 e aprovado em 19 de agosto de 2021.

* Bacharel em Direito pela Pontifícia Universidade Católica de Minas Gerais (PUC-Minas); graduanda em Relações Internacionais pela PUC-Minas; pós-graduanda em Direito Internacional e Direitos Humanos pela PUCMinas; pesquisadora voluntária do Programa de Bolsas de Iniciação Científica (PROBIC) pela PUC-Minas. Advogada. E-mail: menezes.fernanda@outlook.com

** Bacharel em Direito pela Pontifícia Universidade Católica de Minas Gerais (PUC-Minas); mestranda em Constitucionalismo Democrático pela PUC-Minas; pós-graduada em Direito Internacional e Direitos Humanos pela PUC-Minas. Advogada. E-mail: luizascury@gmail.com.

**** Mestre em Direito Privado pela Pontifícia Universidade Católica de Minas Gerais (PUC-Minas). Pós- graduado em Direito dos Contratos; Direito de Empresa; Direito Público; Direito Civil e Processo Civil com ênfase em empreendedorismo. Pós- graduando em Direito Internacional e Direitos Humanos. Graduando em Relações Internacionais. Advogado no Serviço de Assistência Judiciária da PUC-Minas. E-mail: zanetti_matheus1003@gmail.com.
} 


\begin{abstract}
The International Court of Justice (ICJ) is the main jurisdictional body of the United Nations, while the Security Council (UNSC) is the permanent organ of the organization, with the function of maintaining international peace and security. Both represent the most important and prestigious bodies of the institution, so that their relationship and communication is extremely relevant and defined by the Charter of the United Nations and by the Statute of the International Court of Justice. In this sense, it is necessary to understand how this relationship occurs, so that the purpose of this article is to analyze the close relationship between the ICJ and the UNSC, which is done based on the rules defined by the aforementioned international standards, in addition to concrete cases involving such bodies. As a theoretical framework, we use the doctrine of the most renowned jurists and International Relations, which work with the basic concepts to understand the role played by such bodies and their main rules studied and functioning. As an example, we highlight the use of the doctrine of Augusto Cançado Trindade and Malcolm Shaw. The methodology used is based on the comprehensive legal model, with analysis of primary data, such as international standards, and secondary data, such as doctrine. Thus, this article proves to be too pertinent to the field of International Law, since it concerns the communication and relationship between the two organs of the international system, from which it is possible to verify the evolution of International Law and the mechanisms organized by the United Nations for the maintenance of international peace and security.
\end{abstract}

Keywords: International Court of Justice. Security Council. United Nations. Corfu Channel case.

\title{
1 INTRODUÇÃO
}

A Corte Internacional de Justiça (CIJ) e o Conselho de Segurança das Nações Unidas (CSNU) são dois dos principais órgãos da Organização das Nações Unidas (ONU), sendo seu órgão jurisdicional e seu órgão permanente, respectivamente. A CIJ possui como principal função a solução pacífica de controvérsias entre Estados sobre qualquer matéria de Direito Internacional, figurando como uma das Cortes internacionais mais clássicas e de suma importância no Sistema Internacional. Por sua vez, o CSNU possui como função a manutenção da paz e da segurança internacional, contando com diversos mecanismos para implementar e manter a pacificidade do sistema. Nesse sentido, tem-se que, por tratarem-se de finalidade próximas - a manutenção da paz e segurança internacional e a solução pacífica de controvérsias -, a própria Carta da ONU e o Estatuto da CIJ determinam a relação e comunicação entre a CIJ e o CSNU, fazendo-se pertinente, por isso, o estudo dessa relação.

À vista disso, a presente pesquisa tem como objetivo analisar a estreita relação entre a CIJ e o CSNU, o que se faz a partir das regras definidas pelas citadas normas internacionais, além do caso do Estreito de Corfu, único caso já levado à Corte pelo CSNU. Como referencial teórico, utiliza-se a doutrina dos mais renomados juristas e estudiosos das Relações Internacionais, os quais trabalham com os conceitos necessários para se compreender o papel prestado por tais órgãos e suas principais regras procedimentais e de funcionamento, como Augusto Cançado Trindade e Malcolm Shaw, além de outros. A metodologia utilizada parte do modelo jurídico-compreensivo, com análise de dados primários, como normas internacionais, e dados secundários, como a doutrina, pelo qual "[...] utiliza-se do procedimento analítico de decomposição de um problema jurídico em seus diversos aspectos, relações e níveis" (GUSTIN; DIAS, 2002, p. 49).

Para tanto, estudar-se-á, primeiramente, a Corte Internacional de Justiça e suas principais características e procedimentos. Perceber-se-á como a Corte atua por meio de suas 
competências contenciosa e consultiva, além de estudar as fontes de Direito Internacional aplicáveis aos casos perante a Corte, com especial enfoque às decisões judiciais. Adiante, compreender-se-á o funcionamento e as principais configurações do Conselho de Segurança, verificando-se seus principais mecanismos de implementação e manutenção da paz e da segurança internacional, coaduno à análise da questão do poder de veto pelos seus membros permanentes. Por fim, estudar-se-á a relação entre a CJI e o CSNU por meio das disposições da Carta da ONU e do Estatuto da CIJ, analisando-se como se deu a comunicação entre os órgãos no único caso já levado pelo CSNU perante à Corte, o caso do Estreito de Corfu (Reino Unido e Irlanda do Norte vs. Albânia).

\section{A CORTE INTERNACIONAL DE JUSTIÇA}

A da CIJ remonta ao final do século XIX, quando o ímpeto de criar uma corte internacional permanente foi disposto por meio das Conferências de Haia (1897 e 1907). Naquele momento, tinha-se a Corte Permanente de Arbitragem, a qual, conforme explica Shaw (2017) não era uma corte nem era permanente, em que pese ter sido um marco internacional importante para a criação de uma corte internacional. Segundo Lima (2014), "o crescente uso da arbitragem internacional no século XIX por parte dos Estados gerou um importante fenômeno na ciência jurídica: a identificação do sistema de arbitragem internacional como fragmentado e imperfeito sistema judiciário do direito internacional do período" (LIMA, 2014), uma vez que os árbitros priorizavam a solução da controvérsia, a qualquer custo, sobre a aplicação do direito.

Contudo, apenas após a $1^{\text {a }}$ Guerra Mundial houve a criação da Corte Permanente de Justiça Internacional, na década de 1920, de modo que "o objetivo era uma forma de prevenir a eclosão de violência por meio de métodos acessíveis de solução de controvérsias no contexto de uma estrutura organizacional a ser disponibilizada" (SHAW, 2017, p. 803, tradução nossa ${ }^{1}$ ). Desta feita, "nasceria então uma corte verdadeiramente permanente, composta de juízes profissionais, à disposição dos Estados, com um Estatuto e regulamento pré-definido, normas materiais e procedimentais claras e, sobretudo, apta a desenvolver decisões coerentes entre si" (LIMA, 2014).

Com a eclosão da $2^{a}$ Guerra Mundial, todavia, a CPJI foi substituída pela CIJ. A Corte Internacional de Justiça é o principal órgão jurisdicional da ONU e foi criado juntamente com a organização, por sua Carta, em 1945, de maneira que "a CIJ, valendo-se a experiência da predecessora, vem inserida numa arquitetura maior de sociedade internacional cuja principal função é a estabilidade das relações internacionais através da manutenção da paz" (LIMA, 2016, p. 321). Ao instituir a CIJ, o Estatuto da Corte fez com que "as cláusulas facultativas (artigo 35 (5)) e os dispositivos em tratados e convenções (artigo 37) que conferissem jurisdição à CPJI deveriam ser interpretados como estabelecendo jurisdição à CIJ" (LIMA, 2016, p. 319), além de que a Carta da ONU fez questão de taxar a continuidade jurisprudencial da CPJI:

Artigo 92. A Corte Internacional de Justiça será o principal órgão judiciário das Nações Unidas. Funcionará de acordo com o Estatuto anexo, que é baseado no Estatuto da Corte Permanente de Justiça Internacional e faz parte integrante da presente Carta (ORGANIZAÇÃO DAS NAÇÕES UNIDAS, 1945).

Nesse sentido, Lima (2016) esclarece que, com base nessa definição, há de se saber que a Corte é um órgão judiciário, atrelado à Nações Unidas, sendo seu principal órgão judiciário, o que traz três diferentes perspectivas:

\footnotetext{
${ }^{1}$ It was intended as a way to prevent outbreaks of violence by enabling easily accessible methods of dispute settlement in the context of a legal and organisational framework to be made available (SHAW, 2017, p. 803)
} 


\begin{abstract}
A primeira perspectiva conduz à interrogação acerca do peso da função judiciária na sociedade internacional contemporânea e acerca do posicionamento dos Estados em relação ao recurso a um instrumento judiciário de resolução de controvérsias como é a Corte. A segunda soleva a questão do papel da Corte no seio da ONU e nas relações desta com os órgãos políticos da Organização, em particular o Conselho de Segurança. A última refere-se, por sua vez, às relações entre Corte e os outros órgãos judiciários internacionais, sejam eles internos ou externos à ONU (LIMA, 2016, p. 314).
\end{abstract}

O tratado constitutivo da CIJ é o Estatuto da CIJ, o qual é parte da Carta da ONU, de maneira que todos os seus Estados membros são necessariamente Estados membros da CIJ, bem como. Contudo, os Estados que não forem membros da ONU também poderão ser parte da CIJ, se assim for decidido pela Assembleia Geral, a partir da recomendação do Conselho de Segurança. Podem ser partes ativas em casos na Corte apenas Estados, de modo a se tratar de uma Corte cujo Direito Internacional se demonstra em seu modelo demasiado clássico. Nessa esteira, Cançado Trindade (2012) explica:

Trata-se de um mecanismo rigidamente interestatal. O caráter exclusivamente interestatal do contencioso ante a CIJ definitivamente não se tem mostrado satisfatório. Ao menos em alguns casos (no período de 1955 a 2004), relativamente à condição de indivíduos, a presença destes últimos (ou de seus representantes legais), para apresentar, eles próprios, suas posições, teria enriquecido o procedimento e facilitado o trabalho da Corte. Casos do gênero, atinentes sobretudo à situação concreta dos seres humanos afetados, têm se intensificado nos últimos anos perante a CIJ (TRINDADE, 2012, p. 22).

Estados que aderiram à Carta da ONU, podem submeter casos à CIJ, aceitando sua jurisdição, sendo suas decisões vinculativas aos Estados envolvidos. Caso um Estado não cumpra a decisão, é possível submeter uma reclamação ao Conselho de Segurança.

A CIJ possui competência contenciosa e consultiva, o que significa que, além de julgar casos que lhe sejam submetidos, a Corte pode emitir pareceres consultivos requeridos por órgãos da ONU. Logo, "no exercício da competência contenciosa, a Corte julga litígios entre Estados, examinando processos que exultam numa sentença e atuando, portanto, de forma semelhante aos órgãos jurisdicionais internos" (PORTELA, 2021, p. 756). Conforme já explicitado, a Corte julga casos apenas entre Estados, e, nesse sentido, Portela (2021) explica:

Em princípio, apenas aqueles entes estatais que sejam signatários do Estatuto da CIJ podem ser pares em questões perante a Corte. Entretanto, Estados que não sejam signatários do Estatuto ou mesmo membros da ONU também podem ser partes e processos examinados pela CIJ, dentro de parâmetros a serem estabelecidos pelo Conselho de Segurança. Cabe acrescentar que tais entes estatais entram em processos na Corte em condições de igualdade com as demais partes no processo (PORTELA, 2021, p. 756).

Para além de sua competência contenciosa, a Corte pode emitir pareceres consultivos, requeridos, apenas, pela Assembleia Geral, pelo CSNU, e por órgãos da ONU, ou outras entidades devidamente autorizadas pela Assembleia Geral. A Corte pode, contudo, recusar uma opinião consultiva, de modo que "a descrição sobre responder ou não a um pedido de opinião consultiva existe para proteger a integridade da função judicial da Corte e sua natureza como principal órgão das Nações Unidas" (LIMA, 2016, p. 331).

Seja contenciosamente ou consultivamente, a Corte possui competência material sobre qualquer questão de Direito Internacional, principalmente aqueles dispostos na Carta da ONU, ou convenções e tratados em vigor. Assim, "a CIJ deduz sua autoridade não de sua expertise 
setorial num determinado campo do Direito Internacional, mas sim da sua competência geral" (LIMA, 2016, p. 338). Nesse sentido, a Corte possui competência material de controvérsias que tenham por objeto "a interpretação de um tratado; qualquer ponto de Direito Internacional; a existência de qualquer fato que, se verificado, constituiria violação de um compromisso internacional e; d) a natureza ou extensão da reparação devida pela ruptura de um compromisso internacional" (PORTELA, 2021, p. 757). Em que pese a competência material abrangente, essa não é automática, de modo que ao haver uma controvérsia, a Corte não é automaticamente competente a julgá-la - é necessário, primeiramente, o consentimento expresso dos Estados envolvidos. Sobre isso, Portela (2021) explica:

\begin{abstract}
A respeito, a doutrina entende que o Estado pode expressar sua anuência de ser réu perante a CIJ por meio das seguintes possibilidades: previsão em tratado de submissão à Corte de um conflito relativo à aplicação do respectivo ato internacional; decisão voluntária das partes envolvidas em um litígio de submetê-lo à Corte, por meio de um acordo denominado "compromisso", e; aceitação, pelo Estado, da competência da CIJ para decidir acerca do processo contra si proposto por outro Estado (PORTELA, 2021, p. 758).
\end{abstract}

Importante ressaltar, ainda, que o artigo 36 do Estatuto determina o consentimento do Estado por meio "cláusula facultativa de jurisdição obrigatória", pela qual o Estado fica sujeito a ser réu em qualquer processo perante à Corte, independente de novo consentimento. Apontase que o Brasil ainda não aceita a cláusula facultativa de jurisdição obrigatória da CIJ.

Quanto ao procedimento na CIJ, as questões serão submetidas por meio de notificação do acordo especial entre as partes para apresentar o caso à Corte ou por meio de petição escrita, dirigida ao Escrivão, sendo que em ambos os casos as partes e o objeto da controvérsia devem ser indicados. Ao receber a submissão, o Escrivão deve notificar todos os interessados e membros da ONU, por meio do Secretário-Geral, uma vez que o processo é público, a não ser que as partes requeiram o sigilo.

Ao iniciar o processo, a Corte pode determinar medidas cautelares, provisórias, para resguardar os direitos das partes se as circunstâncias assim o requererem. Ademais, a Corte pode tomar decisões acerca da forma e prazos do processo. Antes do início da audiência, a Corte pode ainda intimar as partes a apresentarem documentos, explicações ou requerer algum inquérito ou perícia. Tem-se, com isso, que o procedimento na Corte possui uma fase escrita consistente nos memoriais, contra-memoriais e, se necessário, tréplica - e uma fase oral, consistente na audiência, em que se inclui a oitiva de testemunhas, peritos, agentes, consultores e advogados. Após a audiência, a Corte delibera sobre a sentença, feita pela maioria dos votos, admitindo-se opiniões dissidentes. Em caso de não haver unanimidade, os juízes podem, inclusive, juntar à sentença a exposição de uma opinião individual (PORTELA, 2021). A sentença é definitiva, inapelável e obrigatória. Contudo, há a possibilidade de se pedir esclarecimentos e a revisão, em até dez anos, em caso de fato novo. Por fim, a sentença não possui efeito erga omnes, apenas entre as partes e o caso em específico.

É relevante analisar, bem como, as fontes do Direito Internacional utilizadas pela Corte, sendo aquelas dispostas no artigo 38 do Estatuto:

Artigo 38. 1. A Corte, cuja função é decidir de acordo com o direito internacional as controvérsias que lhe forem submetidas, aplicará:

a) as convenções internacionais, quer gerais, quer especiais, que estabeleçam regras expressamente reconhecidas pelos Estados litigantes;

b) o costume internacional, como prova de uma prática geral aceita como sendo o direito;

c) os princípios gerais de direito reconhecidos pelas Nações civilizadas; 
d) sob ressalva da disposição do art. 59, as decisões judiciárias e a doutrina dos publicistas mais qualificados das diferentes Nações, como meio auxiliar para a determinação das regras de direito.

2. A presente disposição não prejudicará a faculdade da Corte de decidir uma questão ex aeque et bano, se as partes com isto concordarem.

Sobre as fontes, tem que se tratam de fontes primárias as convenções internacionais, o costume internacional e os princípios gerais de direitos, e se tratam de fontes secundárias a jurisprudência internacional e a doutrina. Quanto a isso, Lima (2014) leciona:

Quanto ao costume e aos tratados, não houve discussão acerca de sua entrada na lista de fontes a serem utilizadas pela Corte. Contudo, a discussão entre os membros da Comissão se acirra quanto da escolha dos princípios, da jurisprudência e da doutrina. Ao final, a Comissão decide relegar às decisões judiciais (afasta-se o termo jurisprudência) um papel subsidiário, interpretativo, exatamente pelo receio que a Corte assumisse poderes não desejados pelos Estados. [...] A legislação, ou seja, a produção de normas positivas de direito internacional cabia à vontade dos Estados, entidades soberanas e únicos sujeitos do direito internacional do período. Este entendimento refletiu-se nitidamente no Estatuto da Corte e na maneira como se relacionaria com outras decisões judiciais (LIMA, 2014).

Em que pese a característica secundária das decisões judiciais, a Corte está em constante debate com outros tribunais internacionais:

\begin{abstract}
Hoje, porém, a Corte invoca frequentemente os pronunciamentos de outros tribunais internacionais seja com a finalidade de verificar a existência de certos fatos (como no caso do uso pela Corte da jurisprudência do TPIExI nas controvérsias entre Bósnia e Sérvia e entre Croácia e Sérvia), seja para confirmar a interpretação de um certo tratado, seja para confirmar a existência de um princípio geral. Certamente, esta mudança de abordagem pode ser explicada pelo desejo da Corte de se mostrar aberta ao diálogo com outras jurisdições. Pode-se por outro lado notar que quando ela faz referência a decisões de outras jurisdições, a Corte se preocupa frequentemente em justificar esta referência. A Corte nos explica, portanto, qual o valor que ela atribui às decisões emitidas por certa jurisdição. Ela nos explica qual o motivo pelo qual ela atribui importância à jurisprudência de um tribunal ou a razão pela qual as decisões emanadas por um tribunal sobre certa questão de direito não merecem a mesma atenção que outras decisões emanadas por outro tribunal. Agindo desta forma, a Corte chega substancialmente a estabelecer verdadeiros critérios para a avaliação da autoridade das decisões emanadas por outras jurisdições (LIMA, 2016, p. 342).
\end{abstract}

Logo, tem-se que as decisões da Corte, como já explicitado, apenas é aplicável aos Estados envolvidos e ao caso específico, mantendo-se um papel interpretativo para a jurisprudência internacional, de modo a saber apenas um meio de verificar e delimitar as demais fontes do Direito Internacional. "Contudo, o Estatuto (como toda norma positiva) permanece sempre flexível à vontade do intérprete, muito mais do que a do seu criador. Se homens de 1920 estatuíram que "a Corte não pode legislar", certo é que a Corte ao longo de mais de noventa anos de prática em muito contribuiu para o desenvolvimento do direito internacional" (LIMA, 2014). Nessa esteira, Cançado Trindade (2012) afirma que cada caso é um fim em si próprio, "[...] embora determinadas questões suscitadas em um ou outro caso tenham transcendido a dimensão puramente interestatal e requerido um tratamento que viesse a fomentar a evolução do Direito Internacional" (TRINDADE, 2012, p. 20-21).

Nesse sentido, de evolução do Direito Internacional, tem-se que a Corte tem prestado um importante papel para tanto nas últimas décadas, tendo sido chamada a solucionar diversas controvérsias interestatais, das mais diferentes matérias. Contudo, conforme aponta Lima (2016), a resistência dos Estados em se valer da Corte ainda permanece, o que pode ser 
verificado pela falta de novas adesões à Cláusula Raul Fernandes e a baixa quantidade de tratados que possuem cláusula de adesão ao foro da Corte de maneira prévia. Essa resistência, para Lima (2016), poderia ser melhorada com uma intensa mudança procedimental da Corte, com a utilização de mecanismos que tornem suas decisões mais completas, como o uso de peritos e a possibilidade de se regular a prova testemunhal no seu Estatuto, além da ampliação do rol de possíveis sujeitos no processo, incluindo-se, principalmente, organizações internacionais (LIMA, 2016) e indivíduos (TRINDADE, 2012).

\section{O CONSELHO DE SEGURANÇA DAS NAÇÕES UNIDAS}

O Conselho de Segurança das Nações Unidas é o órgão permanente da ONU, cuja principal função é a manutenção da paz e da segurança internacional, sendo "competente para determinar a existência de qualquer ameaça à paz, ruptura da paz ou ato de agressão, e para proferir recomendações ou decidir medidas que possam manter ou restabelecer a paz e a segurança internacional" (PORTELA, 2021, p. 294). É composto por cinco membros permanentes - Estados Unidos da América (EUA), Reino Unido, França, China e Rússia - e dez membros rotativos, cujo mandato é de dois anos. Quanto a sua principal função como mantenedor da paz e da segurança internacional, determina o artigo 24 da Carta das Nações Unidas:

Artigo 24. 1. A fim de assegurar pronta e eficaz ação por parte das Nações Unidas, seus membros conferem ao Conselho de Segurança a principal responsabilidade na manutenção da paz e da segurança internacionais e concordam em que no cumprimento dos deveres impostos por essa responsabilidade o Conselho de Segurança aja em nome deles (ORGANIZAÇÃO DAS NAÇÕES UNIDAS, 1945).

Para a manutenção da paz e da segurança internacional, o CSNU possui a possibilidade de agir de modo mais rápido e efetivo, possuindo meios de produzir respostas mais específicas às possíveis ameaças ao sistema internacional. Nesse sentido, o Conselho não possui reuniões regularmente, sendo chamado a se reunir em casos de conflitos e crises específicos; qualquer Estado, mesmo os não membros da ONU, pode levar uma problemática ao CSNU. Contudo, desde 2000, algumas reuniões sobre questões específicas foram definidas como regulares, para auxiliar na efetivação da função do CSNU, como em caso de ameaças à paz, a epidemia de HIV/AIDS, entre outras situações (KARNS; MINGST, 2010). Para mais, o presidente do Conselho pode facilitar e iniciar discussões específicas, além de definir quando o CSNU está pronto para decidir sobre alguma questão (KARNS; MINGST, 2010), sendo que a presidência do CSNU é rotativa entre os quinze membros, de modo que há um novo presidente a cada mês.

O Conselho possui diversas medidas à sua disposição para cumprir sua função. Entre elas, Portela (2021) cita as recomendações de interrupção completa ou parcial de relações econômicas, dos fluxos de transportes e de comunicação e das relações diplomáticas. Ademais, uma das mais importantes medidas que podem ser aplicadas pelo Conselho são as missões de paz das Nações Unidas, de maneira que a única forma legítima de intervenção militar no Direito Internacional é aquela autorizada pelo CSNU. Cita-se, bem como, que há a possibilidade de "[...] ações de legítima defesa individual ou coletiva dos Estados membros das Nações Unidas que sofram ataques armados, que perdurarão até que outras medidas sejam tomadas pelo Conselho de Segurança" (PORTELA, 2021, p. 294).

Artigo 39. O Conselho de Segurança determinará a existência de qualquer ameaça à paz, ruptura da paz ou ato de agressão, e fará recomendações ou decidirá que medidas deverão ser tomadas de acordo com os Artigos 41 e 42, a fim de manter ou restabelecer a paz e a segurança internacionais. 


\begin{abstract}
Artigo 40. A fim de evitar que a situação se agrave, o Conselho de Segurança poderá, antes de fazer as recomendações ou decidir a respeito das medidas previstas no Artigo 39 , convidar as partes interessadas a que aceitem as medidas provisórias que lhe pareçam necessárias ou aconselháveis. Tais medidas provisórias não prejudicarão os direitos ou pretensões, nem a situação das partes interessadas. O Conselho de Segurança tomará a devida nota do não cumprimento dessas medidas.

Artigo 41. O Conselho de Segurança decidirá sobre as medidas que, sem envolver o emprego de forças armadas, deverão ser tomadas para tornar efetivas suas decisões e poderá convidar os Membros das Nações Unidas a aplicarem tais medidas. Estas poderão incluir a interrupção completa ou parcial das relações econômicas, dos meios de comunicação ferroviários, marítimos, aéreos , postais, telegráficos, radiofônicos, ou de outra qualquer espécie e o rompimento das relações diplomáticas.

Artigo 42. No caso de o Conselho de Segurança considerar que as medidas previstas no Artigo 41 seriam ou demonstraram que são inadequadas, poderá levar a efeito, por meio de forças aéreas, navais ou terrestres, a ação que julgar necessária para manter ou restabelecer a paz e a segurança internacionais. Tal ação poderá compreender demonstrações, bloqueios e outras operações, por parte das forças aéreas, navais ou terrestres dos Membros das Nações Unidas (ORGANIZAÇÃ̃O DAS NAÇÕES UNIDAS, 1945).
\end{abstract}

Desde o momento da sua criação, os cinco membros permanentes possuem o direito de veto, uma vez que essa foi uma condição colocada pelos EUA e pela União Soviética para a composição do Conselho e sua criação. Em que pese ser controverso, o veto não se trata, hoje, de uma problemática tão complexa, comparado ao período da Guerra Fria, em que EUA e União Soviética raramente concordavam em uma questão. Nessa esteira, sobre o poder de veto dos membros permanentes:

A designação de membros permanentes refletiu a distribuição do poder militar em 1945 e o desejo de garantir a capacidade da ONU de responder rápida e decisivamente a qualquer agressão. Nem os Estados Unidos nem a União Soviética aceitariam a adesão à ONU sem poder de veto. $\mathrm{O}$ veto também refletiu uma aceitação realista por outros de que a ONU não poderia empreender ações de coação nem contra seus membros mais fortes ou sem sua concorrência, mas sempre foi controverso entre pequenos estados e potências médias (KARNS; MINGST, 2010: p. 110, tradução nossa ${ }^{2}$.

Ainda, tem-se que durante a Guerra Fria, principalmente nos anos 1970, a ONU não atuou em diversos conflitos, em razão do impasse do CSNU provocado pelo veto das grandes potências da época:

\begin{abstract}
A Guerra Fria tornou as ações do Conselho de Segurança sobre ameaças à paz e à segurança extremamente problemáticas. Isso resultou em alguns conflitos, como as guerras da França e dos Estados Unidos no Vietnã e as intervenções soviéticas na Tchecoslováquia e na Hungria, que não foram trazidos para a ONU de forma alguma. Uma resposta da ONU à invasão norte-coreana da Coreia do Sul em 1950 foi possível apenas porque a União Soviética estava boicotando o Conselho de Segurança na época (KARNS; MINGST, 2010, p. 112, tradução nossa ${ }^{3}$ ).
\end{abstract}

\footnotetext{
${ }^{2}$ The designation of permanent members reflected the distribution of military power in 1945 and the desire to ensure the UN's ability to respond quickly and decisively to any aggression. Neither the United States nor the Soviet Union would have accepted UN membership without veto power. The veto also reflected a realistic acceptance by others that the UN could not undertake enforcement action either against its strongest members or without their concurrence, but it has always been controversial among small states and middle powers (KARNS; MINGST, 2010, p. 110).

${ }^{3}$ The Cold War made Security Council actions on peace and security threats extremely problematic. It resulted in some conflicts, such as the French and US wars in Vietnam, and Soviet interventions in Czechoslovakia and Hungary, not being brought to the UN at all. A UN response to the North Korean invasion of South Korea in 1950
} 
Por sua vez, durante a década de 1980, o poder e as atividades do CSNU aumentaram demasiadamente, essencialmente em razão de uma mudança de postura da política externa da União Soviética, contribuindo para a efetivação de necessárias intervenções em alguns conflitos, como no caso da guerra entre Irã e Iraque (KARNS; MINGST, 2010). Já durante a década de 1990, a atuação do Conselho em intervenções humanitárias também aumentou, de maneira a atuar frente a mais conflitos armados, utilizando-se das suas funções determinadas pelo capítulo VII da Carta das Nações Unidas. Sendo assim, naquele momento, o CSNU "[...] autorizou mais operações de manutenção da paz e impôs mais tipos de sanções em mais situações do que nunca" (KARNS; MINGST, 2010, p. 113, tradução nossa ${ }^{4}$ ). Com isso, o Conselho se tornou uma das instituições internacionais de maior legitimidade no que diz respeito ao Direito Internacional Humanitário e intervenções militares no mundo. Contudo, essa legitimidade tornou-se o alvo principal de debate no sistema internacional com a inatividade da ONU em Ruanda (1994), no Kosovo (1999) e na invasão no Iraque (2003), os quais demonstraram um trespasse das determinações do CSNU. Essas ocasiões tiveram um efeito dentro do próprio sistema ONU:

O fracasso do Conselho em sua responsabilidade primária de preservar a paz mundial estimulou uma série de outros acontecimentos. Encorajou a Assembleia Geral a assumir uma responsabilidade residual pela manutenção da paz e segurança internacionais, encorajou o Secretário-Geral a assumir um papel mais ativo e acelerou o desenvolvimento de operações de manutenção da paz. Também encorajou, em certa medida, o estabelecimento de alianças militares, como a OTAN e o Pacto de Varsóvia, que surgiram como consequência do início da Guerra Fria e constituíram, com efeito, sistemas regionais de fiscalização que contornavam o Conselho de Segurança (SHAW, 2017, p. 1210, tradução nossa ${ }^{5}$.

Importante salientar, ainda, as concepções de Portela (2021) acerca do veto:

A utilidade do veto, que é tão contestado na ordem internacional, é evitar a retirada da ONU de potências que eventualmente fossem contrariadas, levando ao esvaziamento da entidade, fato que, aliás, contribuiu para o fim da Liga das Nações. Em todo caso, porém, é inegável que o veto macula expressamente o princípio da igualdade entre os Estados, consagrado na própria Carta da ONU, razão pela qual cremos que a única razão para sua manutenção é evidentemente política (PORTELA, 2021, p. 296).

Verificado, portanto, as principais questões concernentes ao funcionamento do Conselho de Segurança e suas características, resta compreender como o Conselho de Segurança e a Corte Internacional de Justiça estão interligados por meio dos seus procedimentos e por suas configurações como principais órgãos do sistema das Nações Unidas.

\section{A RELAÇÃO ENTRE A CIJ E O CSNU}

was possible only because the Soviet Union was boycotting the Security Council at the time (KARNS; MINGST, 2010, p. 112).

${ }^{4}[\ldots]$ and the council also initiated the practice of informal, private consultations and decision making by consensus rather than by formal voting, fueling perceptions of great-power dominance (KARNS; MINGST, 2000, p. 112).

${ }^{5}$ The failure of the Council in its primary responsibility to preserve world peace stimulated a number of other developments. It encouraged the General Assembly to assume a residual responsibility for maintaining international peace and security, it encouraged the Secretary-General to take upon himself a more active role and it hastened the development of peacekeeping operations. It also encouraged in some measure the establishment of the military alliances, such as NATO and the Warsaw Pact, which arose as a consequence of the onset of theColdWar and constituted, in effect, regional enforcement systems bypassing the Security Council (SHAW, 2017, p. 1210). 
A Corte Internacional de Justiça e o Conselho de Segurança da ONU estão conectados por meio de duas principais disposições. A primeira diz respeito à determinação do artigo 36, item 3, da Carta da ONU, de que o Conselho de Segurança pode levar ao conhecimento da Corte alguma controvérsia a ser solucionada:

\begin{abstract}
Artigo 36. 1. O conselho de Segurança poderá, em qualquer fase de uma controvérsia da natureza a que se refere o Artigo 33, ou de uma situação de natureza semelhante, recomendar procedimentos ou métodos de solução apropriados.

2. O Conselho de Segurança deverá tomar em consideração quaisquer procedimentos para a solução de uma controvérsia que já tenham sido adotados pelas partes.

3. Ao fazer recomendações, de acordo com este Artigo, o Conselho de Segurança deverá tomar em consideração que as controvérsias de caráter jurídico devem, em regra geral, ser submetidas pelas partes à Corte Internacional de Justiça, de acordo com os dispositivos do Estatuto da Corte (ORGANIZAÇÃO DAS NAÇÕES UNIDAS, 1945) (Grifo nosso).
\end{abstract}

Nesse sentido, Lima (2016) adverte que esta disposição "[...] não cria uma necessária obrigação ao Conselho de submeter controvérsias à Corte, o que vem confirmado pela rara prática relativa a este dispositivo, ainda que diversas controvérsias de natureza jurídica tenham sido originadas desde a fundação da ONU" (LIMA, 2016, p. 332). Tem-se que a única controvérsia de natureza jurídica já levada à Corte pelo CSNU foi em 1949, no caso do Estreito de Corfu. No caso, o Reino Unido levou a Albânia perante à Corte, sendo esse o seu primeiro caso contencioso, quase uma década após a finalização dos trabalhos da CPJI.

$\mathrm{O}$ caso iniciou-se em razão de ataques terem sido feitos às navegações britânicas no Estreito de Corfu, além de outro incidente em que houve a explosão de minas submarinas que culminaram na morte de oficiais britânicos, na qual a Albânia alegou que a entrada do navio britânico havia sido irregular, sem prévia autorização albanesa. Assim, o governo britânico, unilateralmente, procedeu à varredura de minas submarinas no território albanês, o que foi alegado, novamente, pela Albânia, não ter sido autorizado (CORTE INTERNACIONAL DE JUSTIÇA, 1949). O governo albanês levou a questão ao Secretário-Geral da ONU e, por recomendação do Conselho de Segurança, o caso foi levado à CIJ. Assim, a recomendação do CSNU determinava:
O Conselho de Segurança,
Tendo considerado as declarações de representantes do Reino Unido e da Albânia sobre uma disputa entre o Reino Unido e a Albânia decorrente de um incidente em 22 de outubro de 1946 no Estreito de Corfu em que dois navios britânicos foram datados por minas, com a consequente perda de vidas e ferimentos em suas tripulações,
Recomenda que os governos do Reino Unido e da Albânia encaminhem imediatamente a disputa à Corte Internacional de Justiça, de acordo com as disposições do Estatuto da Corte (CONSELHO DE SEGURANÇA, 1947, tradução nossa ${ }^{6}$.

Na mesma medida em que o CSNU não possui a obrigatoriedade de submeter controvérsias jurídicas à Corte, a CIJ bem como não possui a obrigatoriedade de avaliar a controvérsia, a não ser que assim seja requerido pelos Estados de maneira expressa. Desta feita, tem-se que a relação entre tais órgãos provisionados pelo artigo 36 (3) constitui uma

\footnotetext{
${ }^{6}$ The Security Council, having considered statements of representatives of the United Kingdom and Albania concerning a dispute between the United Kingdom and Albania arising out of an incident on 22 October 1946 in the Straits of Corfu in which two British ships were dated by mines, with resulting loss of life and injury to their crews, recommends that the United Kingdom and Albanian Governments should immediately refer the dispute to the International Court of Justice in accordance with the provisions of the Status of the Court.
} 
comunicação demasiada superficial para estabelecer uma relação de fato relevante, uma vez que não trata-se de algo vinculativo e, com a evolução do Direito Internacional, acabou por cair em desuso. Nessa esteira, ressalta-se Lima (2016), para o qual:

\begin{abstract}
Neste aspecto, não é o suficiente que o Conselho insira nas suas resoluções convites genéricos aos Estados de direcionarem-se à Corte, como até então aconteceu. O Conselho deve sobretudo interrogar-se sobre a oportunidade de recomendar específicas controvérsias à Corte. Uma recomendação em tal sentido por parte do Conselho é efetivamente destinada a criar uma notável pressão sobre as partes na controvérsia para que tomem o "caminho de Haia" para encontrar uma solução (LIMA, 2016, p. 333).
\end{abstract}

Para além disso, o segundo dispositivo que preleciona uma relação entre a CIJ e o CSNU é o artigo 94, item 2, da Carta da ONU, pelo qual um Estado pode recorrer ao CSNU para que este tome medidas no caso de descumprimento de alguma sentença da Corte:

\begin{abstract}
Artigo 94. 1. Cada Membro das Nações Unidas se compromete a conformar-se com a decisão da Corte Internacional de Justiça em qualquer caso em que for parte.

2. Se uma das partes num caso deixar de cumprir as obrigações que lhe incumbem em virtude de sentença proferida pela Corte, a outra terá direito de recorrer ao Conselho de Segurança que poderá, se julgar necessário, fazer recomendações ou decidir sobre medidas a serem tomadas para o cumprimento da sentença (ORGANIZAÇÃO DAS NAÇÕES UNIDAS, 1945).
\end{abstract}

Nesse sentido, o citado artigo é de extrema importância e demonstra o nível de vinculação ao qual as partes de um caso solucionado pela Corte se submetem, estando submetidas, por isso, também à possíveis medidas do CSNU, inclusive relativas ao uso da força. O CSNU decide se vai tomar medidas ou não para o cumprimento da sentença, podendo, bem como, fazer apenas recomendações (LIMA, 2016). Ressalta-se, ainda, que apenas as partes envolvidas na controvérsia podem recorrer ao CSNU para requerer o cumprimento de uma sentença; a intervenção de um terceiro só é admitida quando o não cumprimento da sentença inflija diretamente o terceiro Estado interventor.

Entretanto, mais uma vez, tem-se que o dispositivo só foi utilizado uma vez, no caso Estados Unidos vs. Nicarágua, no qual não houve nenhuma medida efetiva tomada pelo CSNU, pois os Estados Unidos vetaram a proposta de resolução que previa o cumprimento da sentença, em que pese ser expressamente proibido que um membro do Conselho vote em uma controvérsia da qual é parte (ORGANIZAÇÃO DAS NAÇÕES UNIDAS, 1945). Nesse sentido, tem-se que esse dispositivo também não figura como suficiente para estabelecer uma relação profunda, capaz, inclusive, de trazer maior segurança jurídica nas recomendações de ambos os órgãos, por meio da sua prévia comunicação e harmonização da interpretação do Direito Internacional. Ademais, conforme aponta Lima, "uma intervenção do Conselho de Segurança em casos de não execução de uma sentença contribui evidentemente a tornar mais efetiva a ação da Corte" (LIMA, 2016, p. 334).

\title{
5 CONSIDERAÇÕES FINAIS
}

A presente pesquisa teve como objetivo analisar a relação entre a CIJ e o CSNU, a partir das disposições da Carta da ONU, primordialmente. Estudou-se, primeiramente, a CIJ, seu funcionamento, procedimentos e principais características. Verificou-se que a Corte trata-se de um dos principais órgãos do sistema internacional, e é o principal órgão jurisdicional da ONU, tratando-se, ainda, de uma instituição representativa da tradicionalidade do Direito Internacional, principalmente em razão da sua competência ser atrelada apenas aos Estados. 
Adiante, estudou-se o CSNU, perpassando pelas principais características do órgão permanente da ONU, cuja função é a manutenção da paz e da segurança internacional. Verificou-se, na ocasião, que o CSNU trata-se de um órgão que tem à sua disposição diversas medidas para o cumprimento de sua finalidade, sendo imprescindível para legitimar a mais extrema das medidas, a saber o uso da força, por meio das intervenções militares, como as missões de paz da ONU.

Em seguida, estudou-se a relação entre a CIJ e o CSNU, essencialmente no que diz respeito às disposições do artigo 36 (3) e 94 (2) da Carta da ONU, as quais dispõem sobre a possibilidade do CSNU submeter uma controvérsia jurídica à CIJ e a possibilidade de, no caso de não execução de uma sentença da Corte, um Estado poder recorrer ao CSNU, respectivamente. Viu-se que ambos os dispositivos foram utilizados apenas uma vez, o que demonstra o seu desuso e inefetividade para que haja uma comunicação e relação profunda entre os órgãos. Nesse sentido, entende-se por inefetividade em razão das eventuais vantagens que haveria no caso de uma relação estreita, como a harmonia entre as concepções acerca do Direito Internacional entre a CIJ e CSNU, trazendo mais segurança jurídica ao Sistema Internacional. Para mais, a relação entre os órgãos poderia ser benéfica, bem como, para reafirmar o posicionamento e a vinculação das suas decisões, uma vez que a CIJ é uma das Cortes mais respeitadas por Estados e o CSNU possui a sua disposição a possibilidade de uso da força, entre outras medidas, ambas hipóteses necessárias para aumentar a aderência dos Estados às normas do sistema ONU.

Conclui-se, desta feita, que os dispositivos trazidos pela Carta da ONU não são suficientes para que estabelecer uma relação demasiada solene entre a CIJ e o CSNU, o que ocorre porque os órgãos, em si, não utilizam deles, fazendo com que esses caiam em desuso, haja visto não se tratarem de disposições obrigatórias. Os efeitos disso recaem, principalmente, nos próprios órgãos, no que diz respeito à vinculação de suas decisões e assertividade dos seus posicionamentos, seja sobre política internacional ou sobre o Direito Internacional. Com efeito, sendo estes órgãos compostos por, e pensados para, os Estados, tem-se, por conseguinte, que esses são afetados diretamente, a partir da ausência de uma maior harmonia doutrinária e jurisprudencial e segurança jurídica no Sistema Internacional.

\section{REFERÊNCIAS}

CONSELHO DE SEGURANÇA DAS NAÇÕES UNIDAS. Resolution of 9 April 1947. Nova York, 1947. Disponível em: https://documents-ddsny.un.org/doc/RESOLUTION/GEN/NR0/042/18/PDF/NR004218.pdf?OpenElement. Acesso em 10 de jul. 2021.

CORTE INTERNACIONAL DE JUSTIÇA. Cofu Channel Case. Haia, 9 de abr. 1949. Disponível em: https://www.icj-cij.org/public/files/case-related/1/001-19490409-JUD-01-00EN.pdf. Acesso em 10 de jul. 2021.

GUSTIN, Miracy Barbosa de Sousa; DIAS, Maria Tereza Fonseca. (Re)pensando a pesquisa jurídica: teoria e prática. Belo Horizonte: Del Rey, 2002.

LIMA, Lucas Carlos. As decisões da Corte Internacional de Justiça como elemento de desenvolvimento do Direito Internacional. In: DAL RI Júnior, Arno; MOURA, Aline Beltrame de. (Org.). Jurisdição Internacional: Interação, Fragmentação,

Obrigatoriedade. Ijuí: Unijuí, 2014, p. 317-348. 
LIMA, Lucas Carlos; PALCHETTI, Paolo. Os 70 anos da Corte Internacional de Justiça: retrospecto e perspectivas futuras do principal órgão judiciário da Organização das Nações Unidas. In: JUBILUT, Liliana Lyra; SILVA, João Carlos Jarochinski; RAMINA, Larissa. A ONU aos 70: contribuições, desafios e perspectivas. Boa Vista: Editora da UFRR, 2016.

KARNS, Margaret P.; MINGST, Karen A. International organizations: the politics and processes of global governance. 2. ed. Colorado: Lynne Rienner Publishers, 2010.

ORGANIZAÇÃO DAS NAÇÕES UNIDAS. Carta das Nações Unidas, 1945. Disponível em: https://www.un.org/en/about-us/un-charter. Acesso em 27 de jun. 2021.

PORTELA, Paulo Henrique Gonçalves. Direito Internacional Público e Privado. 13. ed. rev., atual. e ampl. Belo Horizonte: JusPodivm, 2021.

SHAW, Malcolm N. International law. 8. ed. Cambridge: Cambridge University Press, 2017.

TRINDADE, Antônio Augusto Cançado. Os tribunais internacionais contemporâneos. Brasília: FUNAG, 2013. 